\title{
ASPECTOS CLÍNICOS, PATOLÓGICOS E TERAPÊUTICOS DA PLACA EOSINOFÍLICA FELINA - RELATO DE CASO
}

\author{
Jackson Suelio de Vasconcelos I \\ Higor Vinícius da Silva Camelo" \\ Letícia Ferreira do Nascimento " \\ Lídia Stefânia Vilela Medeiros"
}

\begin{abstract}
RESUMO
Um mesmo felino pode apresentar mais de uma forma de diferenciação histológica em cada uma das apresentações clínicas do complexo granuloma eosinofílico. O diagnóstico definitivo é baseado no histórico clínico, citologia e exame histopatológico. O presente trabalho tem como objetivo descrever os aspectos clínicos, terapêuticos, patológicos da placa eosinofílica felina. O primeiro caso ocorreu em um gato de dois anos de idade que apresentava lesão em toda extensão do abdome com úlceras e exsudato, pulgas e anorexia. O segundo, tratava-se de uma gata de 11 anos que tinha lesão localizada no abdome, a presença de úlceras, exsudato e pulgas. Em ambos os casos, os hemogramas mostraram eritropenia leve, leucocitose, eosinofilia e trombocitopenia. No exame citopatológico foram observadas células degeneradas semelhantes a eosinófilos. No exame histopatológico constatouse presença de mastócitos, plasmócitos, com exocitose eosinófilica e também colagenólise. Foi adotado antibioticoterapia a base de enrofloxacina na dose de $5 \mathrm{mg} / \mathrm{kg} / \mathrm{pv}$ a cada 24 horas por 10 dias, corticóide, terapia com predinosolona na dose de $1 \mathrm{mg} / \mathrm{kg} / \mathrm{pv}$ por 10 dias e assepsia nos ferimentos com clorexidina a $0,2 \%$. Ao término do tratamento, os animais se recuperaram totalmente. 0 diagnóstico de placa eosinofílica felina foi realizado com base no histórico clínico e com os resultados dos exames citopatológicos, histopatológicos e na resposta terapêutica.
\end{abstract}

PALAVRAS-CHAVE: Complexo Granuloma Eosinofílico. Lesões em Placas. Colagenólise. Lesão Ulcerativa.

Professor, Curso de Medicina Veterinária. Doutor em Ciência e Saúde Animal. E-mail: veterinariojsv@yahoo.com.br. Departamento de Medicina - FACENE. CEP: 58067-695. João Pessoa, Paraíba. Brasil. ORCID ID: https://orcid.org/0000-0003-1302-8451

Acadêmicos do Curso de Medicina Veterinária. Departamento de Medicina. João Pessoa, Paraíba. Faculdades Nova II Esperança - FACENE. CEP: 58067-695. João Pessoa, Paraíba. Brasil. ORCID ID: https://orcid.org/0000-0003-4187-5287; https://orcid.org/0000-0002-4963-0797; https://orcid.org/0000-0002-5112-0614

Submissão: 16/04/2019 Aceito: 08/08/19

DOI: 10.17695/revcsnevol17n3p57-64 


\section{INTRODUÇÃO}

As doenças de pele são as principais ocorrências em clínicas veterinárias especializadas em pequenos animais, representando 25,2\%. ${ }^{1,2}$ As dermatopatias não tumorais mais diagnosticadas na espécie canina são a hipersensibilidade a picada de pulgas e mosquitos, piodermites bacterianas, atopia, dermatofitoses entre outras. ${ }^{3}$ Dentre as dermatopatias, que afetam os felinos, a terceira mais diagnosticada foram as alérgicas em estudo retrospectivo realizado no Rio Grande do Sul. ${ }^{4}$ O granuloma eosinofílico felino (CGE) é a doença alérgica muito frequente na forma de placa eosinofílica, granuloma linear eosinofílico e a úlcera indolente. 5

A placa eosinofílica é uma lesão cutânea pruriginosa, saliente, caracterizada clinicamente por apresentar lesão ulcerada e placoide8. Pode ocorrer em qualquer local do corpo, porém é mais frequente no abdome ventral, afetando exclusivamente os gatos. 6 A identificação pode ser difícil, devido a outras enfemidades, pertencentes ao CGE, serem semelhantes. ${ }^{7}$ Ospadrõeshistológicos de cada uma das apresentações clínicas são diferentes, porém todas se caracterizam por um infiltrado inflamatório formado em maior quantidade de eosinófilos e variado número de mastócitos, histiócitos, linfócitos e focos de colagenólise. Embora haja diferenciação histológica em cada uma das identificações clínicas, um mesmo felino pode apresentar mais de uma forma. ${ }^{8}$ As causas para o desenvolvimento do CGE são variadas, podendo estar associada com quadros infecções virais, bacterianas, parasitárias, autoimunes, traumáticos, genodermatose, alérgicos e idiopáticos. ${ }^{9}$

A terapia objetiva eliminar o agente causal. No entanto, quando estiver associado a uma alteração secundária, deve-se tratar sintomaticamente. ${ }^{8}$ Geralmente, os felinos afetados respondem bem a terapia à base de glicocorticóides sistêmicos e anti- histamínicos, devido a resistência aos efeitos colaterais e antibiótico terapia. ${ }^{10}$ Diante do exposto, o presente trabalho tem como objetivo descrever os aspectos clínicos, terapêuticos, patológicos da placa eosinofílica felina.

\section{MATERIAL E MÉTODOS}

A pesquisa foi aprovado pelo Comitê de Ética no Uso de Animais (CEUA) da Universidade Federal da Paraíba, sob número: 4463030519. Foram tratados dois gatos em uma clínica veterinária localizada no município de João Pessoa, Paraíba, nos meses de janeiro e fevereiro de 2015. O primeiro caso, um felino, sem raça definida (SRD) com dois anos de idade e o segundo uma felina sem raça definida (SRD), com 11 anos. Para o diagnóstico, além dos exames físicos, fez-se também hemogramas, exame citopatológico e histopatológico. Os hemogramas foram realizados no Laboratório de Análises Clínicas Veterinárias (LACLEVET) e os citopatológicos na Clínica Veterinária São Francisco, ambos no município de João Pessoa-PB. Enquanto que os histopatológicos no Laboratório de Patologia Veterinária (LPV) do Centro de Ciências Agrárias (CCA) da Universidade 
Federal da Paraíba (UFPB), no minicípio de Areia, Paraíba.

As amostras de sangue para os hemogramas foram colhidas em tubo vacutainer contendo EDTA. Colheu-se amostra por punção aspirativa com agulha fina (PAAF) calibre de $0,4 \mathrm{~mm}$, colocadas em lâminas de vidro foscada $26 \times 76 \mathrm{~mm}$ e coradas pela técnica do panótico rápido para os citopatológicos. As amotras para histopatologia foram coletadas através de biópsias excisionais, fixadas em formalina tamponada a 10\%, processadas rotineiramente para histotécnica e coradas com hematoxilina e eosina (HE).

O diagnóstico de placa eosinofílica felina foi realizado com base no histórico clínico, nos exames dermatológicos, resultados de exames laboratoriais, histopatológico e em alguns casos no acompanhamento, durante o tratamento. A terapia foi realizada a base de enrofloxacina na dose de $5 \mathrm{mg} / \mathrm{kg} / \mathrm{pv}$, corticoterapia com predinosolona na dose de $1 \mathrm{mg} / \mathrm{kg} / \mathrm{pv}$ e assepsia nos ferimentos com clorexidina a $0,2 \%$.

\section{RESULTADOS E DISCUSSÃO}

No primeiro caso, o gato apresentava lesão em toda extensão do abdome com úlceras e exsudato, presença de pulgas e anorexia (Figura 1a). Já o felino do segundo caso, apresentava lesão placoide localizada no abdome, presença de úlceras e exsudato e pulgas (Figura 1b). Nos hemogramas ambos apresentaram eritropenia leve, leucocitose, eosinofilia e trombocitopenia.
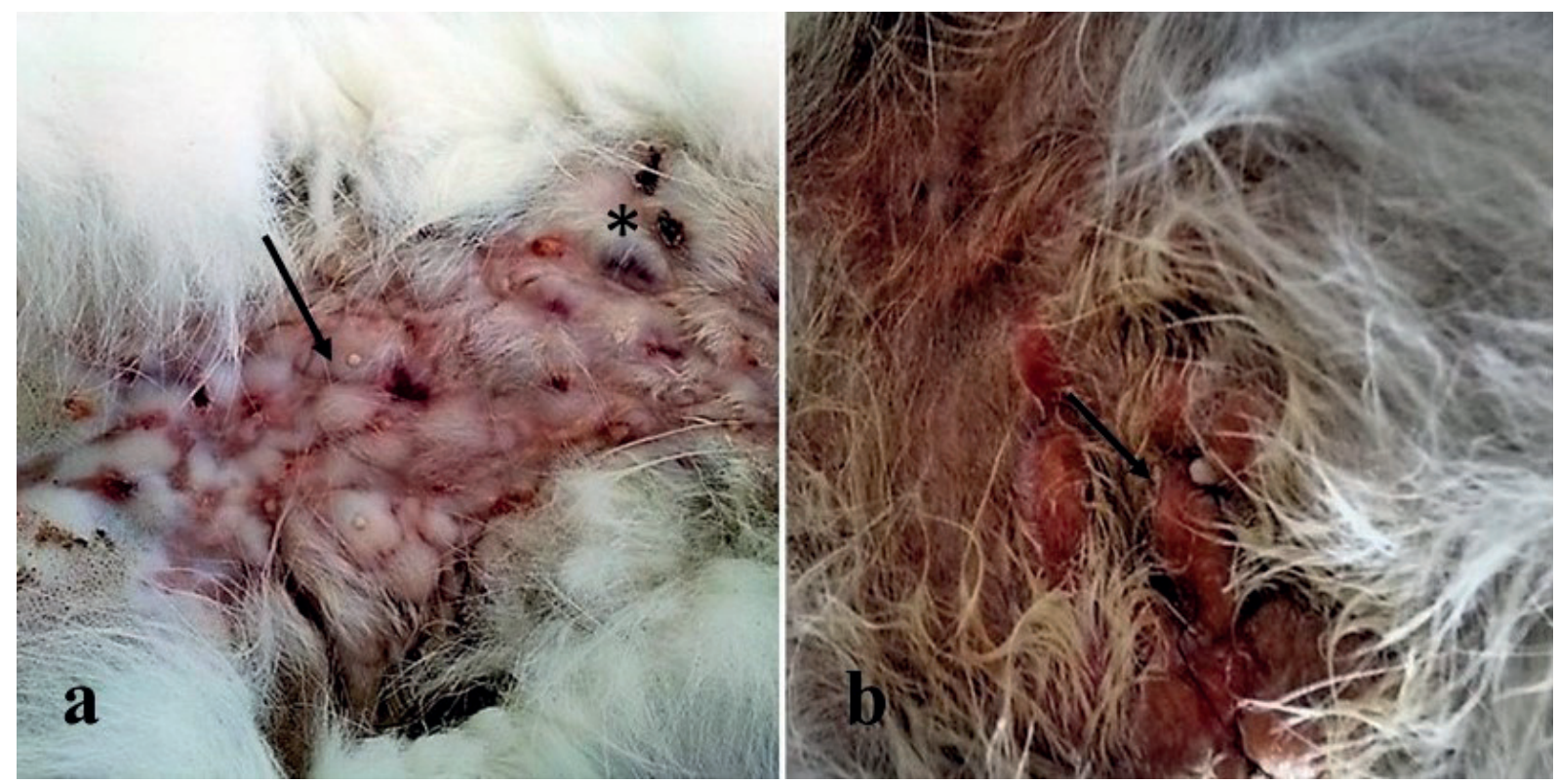

FIGURA 1. a) Felino de 2 anos. Lesão ulcerativa e exsudativa, distribuída em toda extensão do abdome (seta e asterisco). Caso 1. b) Felina de 11 anos. Lesão ulcerativa e exsudativa, distribuída de forma localizada no abdome. Caso 2. 
Os achados citopatológicos em ambos caracterizaram-se por células degeneradas semelhantes à eosinófilos. Os histopatológico, em ambos os casos, foram observados na epiderme acantose e espongiose. Na derme constatou-se infiltração de eosinofílico, com presença de mastócitos, plasmócitos, com exocitose eosinófilica e também colagenólise (Figuras 2, 3 e 4). No tratamento, foi adotado antibioticoterapia a base de enrofloxacina na dose de $5 \mathrm{mg} / \mathrm{kg} / \mathrm{pv}$ a cada 24 horas durante 10 dias, corticóide terapia com predinosolona na dose de $1 \mathrm{mg} / \mathrm{kg} / \mathrm{pv}$ por 10 dias e assepsia nos ferimentos com clorexidina a $0,2 \%$. Para o controle das pulgas foi recomendado o uso de selectina a $6 \%$, aplicada por via tópica (spot on) em única aplicação. Ao término do tratamento os animais recuperaram-se totalmente.
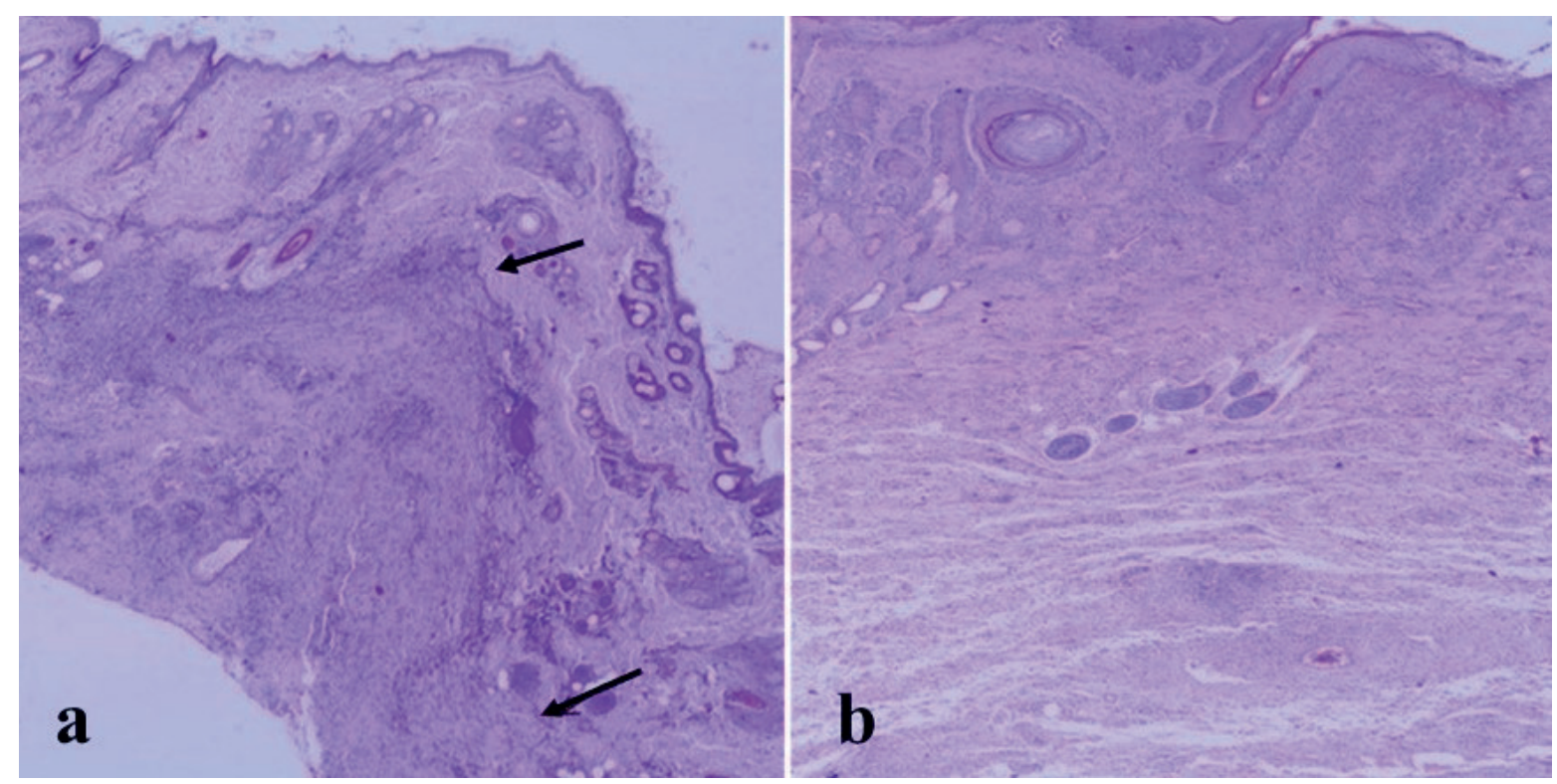

FIGURA 2. a) Marcada delimitação da área da derme acometida pela inflamação e a área normal (setas). HE, Obj. 40x. Caso 1. b) observa-se infiltrado eosinofílico que se estende da derme superficial até a derme profunda. HE, Obj. 4x. Caso 2.

O diagnóstico de placa eosinofílica felina foi realizado com base no histórico dos animais, exame físico geral e dermatológico, associado à avaliação dos padrões macroscópicos e histopatológicos das lesões cutâneas. A colheita de amostras para descartar diagnósticos diferenciais e para investigação da causa primária, como as causas de doenças alérgicas, com a realização de testes de triagem com eliminação de ectoparasitas, dietas de eliminação e testes intradérmicos, quando necessário, podem ser realizados. ${ }^{11}$ Estudos observaram que a hipersensibilidade a picada de pulgas (DAPP) é um dos fatores primários para o desencadeamento da placa eosinofílica felina. ${ }^{3}$ No presente estudo, em ambos os casos, os animais encontravam-se infestados de pulgas. Contudo, não foi observada sazonalidade, apesar da literatura associar a doença a infestação por pulga. ${ }^{12}$ Também não se constatou predisposição quanto ao sexo, semelhante ao que é descrito em outros trabalhos. ${ }^{6,7}$ 


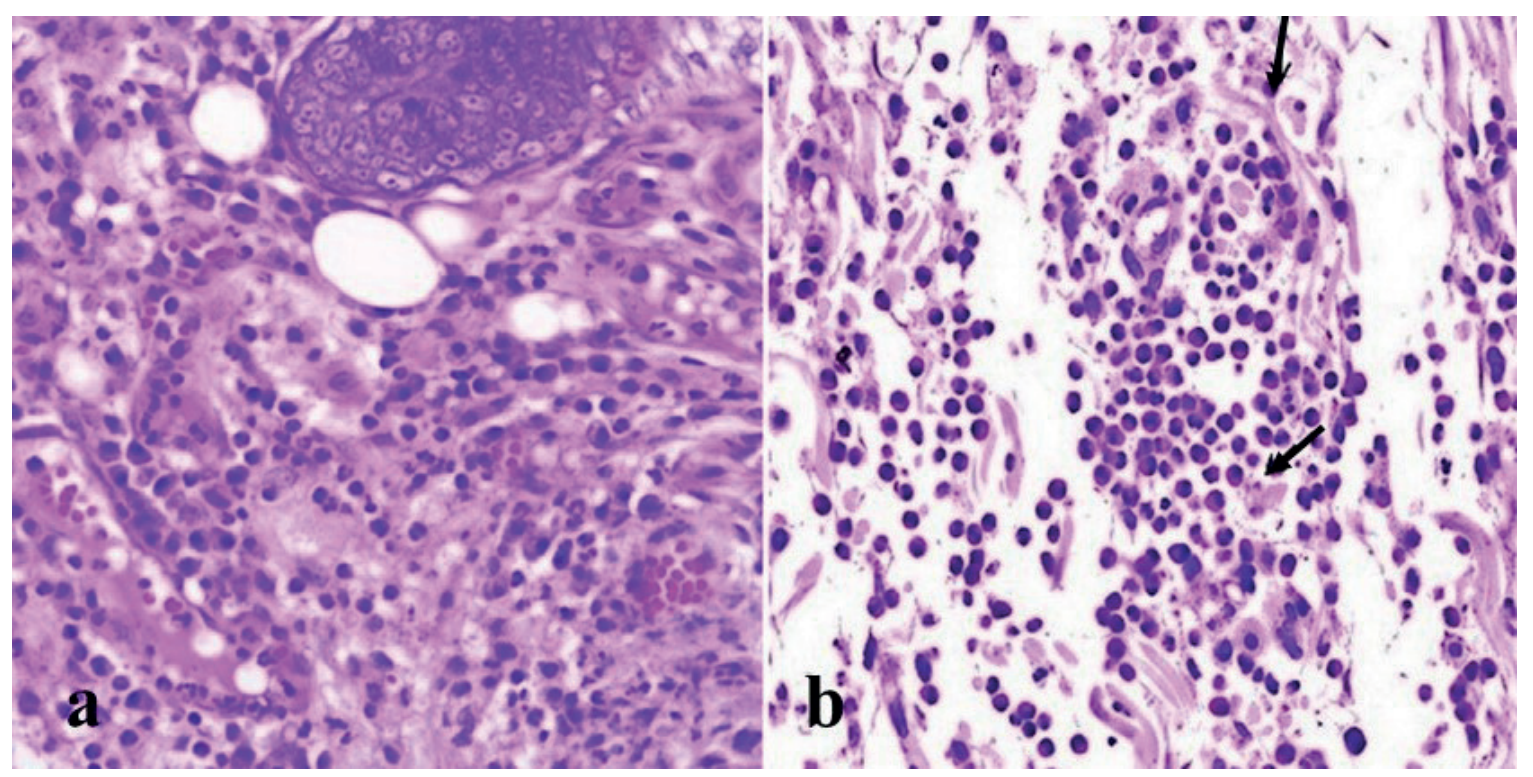

FIGURA 3. Caso 2: a) Intenso infiltrado eosinofílico na derme superficial. HE, Obj. 40x. b) observa-se intenso infiltrado eosinofílico e degradação do colágeno (setas). HE, Obj. 40x.

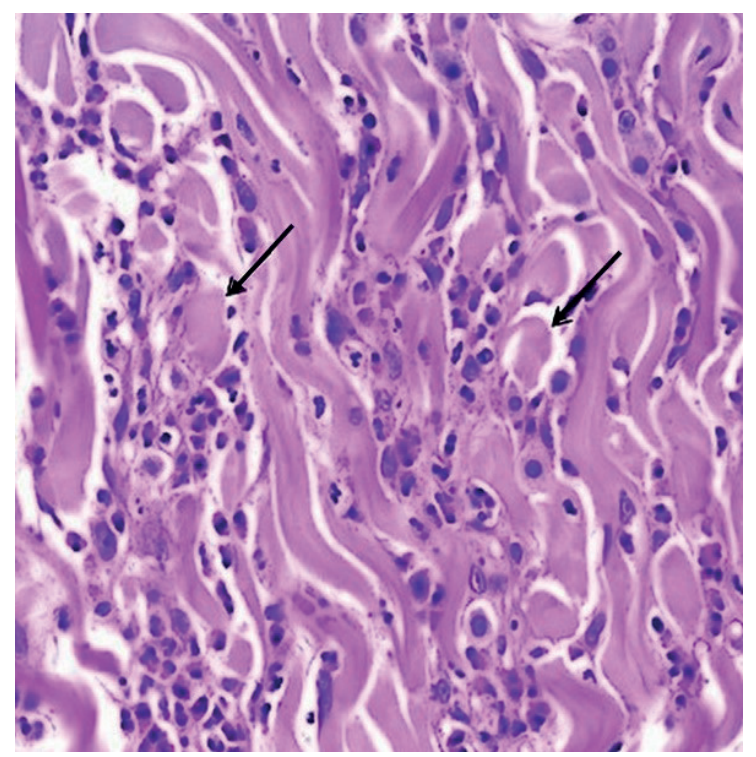

FIGURA 4. Caso 1: Entre as fibras de colágeno observa-se grande quantidade de eosinófilos, plasmócitos, mastócitos e macrófagos. Associado a intensa degradação de colágeno (colagenólise), denominadas figuras em chamas (seta). HE, Obj. 40x.

A apresentação clínica dessa dermatopatia caracterizou-se por lesões placóides extensivas e por placa localizada, ambas associadas a presença de úlceras e exsudato, no abdome. Esses achados, junto com a distribuição anatômica, corroboram com outro estudo. ${ }^{8}$ No entanto, a distribuição anatômica das lesões já foram observadas em outros sítios anatômicos, tais como, região inguinal, parte interna ou externa das extremidades pélvicas, pescoço e nos espaços interdigitais, cursando com prurido. 7,13 
$\mathrm{Na}$ citologia, a observação de eosinófilos degenerados, na colheita da amostra pela PAAF, correspode ao descrito na literatura. ${ }^{14}$ Entretanto, é descrito que, além de eosinófilos degenerados e intáticos, também ocorra a presença de bactérias nos casos em que há infecção secundária. ${ }^{12}$ No presente estudo, os achados histopatológicos revelaram lesões nos dois casos, caracterizadas por apresentarem infiltrado inflamatório composto por maior quantidade de eosinófilos, mastócitos e grau moderado colagenólise. Esse padrão inflamatório é característico das apresentações clínicas relacionadas com o CGE. ${ }^{8}$ Em alguns casos, a placa eosinofílica felina pode ser caracterizada como uma dermatite eosinofílica perivascular hiperplásica superficial ou profunda, podendo serem constatados micro abscessos eosinofílicos. ${ }^{12}$ Em nível de epiderme, também pode ser observada paraceratose, acantose com zonas

\section{CONCLUSÕES}

O diagnóstico de placa eosinofílica felina foi realizado com base no histórico clínico, associado ao exame físico, aos resultados dos exames citopatológicos caracterizados por apresentar grande quantidade de eosinófilos degenerados. $O$ padrão histopatológico apresentou alterações na epiderme e derme, ulceradas recobertas de tecido fibronecrótico, espongiose e vesiculação intraepidérmica eosinofílica. Enquanto que na derme as lesões indicam celulite eosinofílica, com ou sem a presença de mastócitos ou plasmócitos, podendo ainda ocorrer foliculite eosinofílica. ${ }^{15}$

Como se trata de uma doença de caráter secundário, seguido de doença primária de caráter alérgico, o tratamento incluiu eliminação da causa primária, o qual foi realizado com ectoparasiticida tópico e, consequentemente, controlando a DAPP, associado ao uso de antibiótico e corticoide. ${ }^{12}$ Tambémérelatado que, ocasionalmente, ocorra a melhora ou mesmo a remissão completa das lesões, após a utilização da antibioticoterapia, sendo, portanto recomendada como tentativa clínica quando houver evidências, citológicas, ou histopatológicas de pioderma, sendo a doxiciclina, cefadroxil, amoxicilina-clavulanato e enrofloxacina as opções indicadas. ${ }^{16}$ os quais foram compatíveis com resposta alégica. A terapia empregada a base de predinisolona, enrofloxacino, associado ao uso de medicamento pulguicida levou a resposta satifatória com desaparecimento das lesões e consequente cura do dos animais.

\section{CLINICAL, PATHOLOGICAL AND THERAPEUTIC ASPECTS OF THE FELINE EO- SINOPHILIC PLAQUE - CASE REPORT}

\section{ABSTRACT}

Although there is histological differentiation in each of the clinical presentations of the eosinophilic granuloma complex, in one cat, it can be present more than one form. The definitive 
diagnosis is based on clinical history, cytology, and histopathological examination. Two cases of feline eosinophilic plaque are described in the municipality of João Pessoa, Paraíba. The first case affected a two years old male cat who had lesions throughout all the abdomen extension with ulcers and exudate, and the presence of fleas and anorexia. The second was an 11-year-old female cat with a localized lesion in the abdomen, with the presence of ulcers and exudate, fleas had also been visualized. On the hemogram, both presented mild erythropenia, leukocytosis, eosinophilia, and thrombocytopenia. And, in the cytopathological examination, degenerate cells similar to eosinophils were observed. Histopathological examination, in both cases, reveals in the epidermis acanthosis and spongiosis. About the dermis, the presence of eosinophilic infiltrate, with the presence of mast cells, plasma cells, with eosinophilic exocytosis, and also collagenolysis. It was adopted an antibiotic therapy with enrofloxacin base at a dose of $5 \mathrm{mg} / \mathrm{kg} / \mathrm{bw}$ every 24 hours for ten days, corticosteroid therapy with prednisolone at a dose of $1 \mathrm{mg} / \mathrm{kg} / \mathrm{bw}$ for ten days and asepsis in wounds with chlorhexidine $0,2 \%$. At the end of the treatment, the animals recovered completely. The diagnosis of the feline eosinophilic plaque was based on the clinical history and the results of cytopathology, histopathology, and therapeutic response.

KEYWORDS: Eosinophilic Granuloma Complex. Plaque Injuries. Collagenolysis. Ulcerative Injury.

\section{REFERÊNCIAS}

1. Rosenkrantz WS. Dermatite Miliar e Complexo do Granuloma Eosinofílico. In: Birchard SJ. \& Sherding RG: Manual Saunders-Clínica de Pequenos Animais. São Paulo: Editora Roca; 1998. p. 975 - 90.

2. Vasconcelos JS, Oliveira-Neto TS, Nascimento HHL, Barbosa FMS, Rezende FYS, Oliveira LG, Lecena RB, Dantas AFM. Caracterização clínica e histopatológica das dermatites alérgicas em cães. Pesq. Vet. Bras. 2017: 37(3):248-56.

3. Souza TM, Fighera RA, Schmidt C, Requias AH, Brum JS, Martins TB, Barros CSL. Prevalência das dermatopatias não-tumorais em cães do município de Santa Maria, Rio Grande do Sul (2005-2008). Pesq. Vet. Bras. 2009: 29(2):157-62.

4. Scherer HA. Estudo Retrospectivo de Dermatopatias em Gatos Através de Diagnóstico Histopatológico Realizado no Setor de Patologia Veterinária da UFRGS, Porto Alegre (1990 2012) [dissertação]. Porto Alegre: Universidade Federal do Rio Grande do Sul; 2015.
5. Cintra CA, Paulino-Júnior D, Brum AM, Dias LGGG. Granuloma Linear Eosinofílico em felino: Relato de caso. Cent. Cient. Conh. 2013; 9(17): 1571-82.

6. Chandler EA, Gaskell CJ, Gaskel, RM. Clinica e Terapêutica em Felinos. 3 ed. São Paulo: Roca; 2006.

7. Gross TL, Ihrke PJ, Walder EJ, Affolter VK. Skin diseases of the dog and cat: Clinical and histopathologic diagnosis. 2nd. Ed. Oxford: Blackwell; 2009.

8. Hargis AM, Ginn PE. O Tegumento. In: Zachary JF \& Mcgavin MD (Org.): Bases da Patologia em Veterinária. Tradução da 5th. ed. Rio de Janeiro: Editora Elsevier; 2013. p. 975-12.

9. Bloom PB. Canine and feline eosinophilic skin diseases. Veterinary Clinics of North America: Small Animal Practice, v. 36, n. 1, 2006. p. 141-60. 10. RodriguesA.Complexogranulomaeosinofílico felino. Areia - PB: Universidade Federal do 
Rio Grande do Sul; 2016.

11. Cerdeiro AP, Fam AL. Complexo granuloma eosinofílico em felinos domésticos: revisão de literatura. In: $38^{\circ}$ Congresso Brasileiro Da Anclivepa. Recife/PE: Centro de Convensões. 2017; Maio 3-5. p. 2039.

12. Hnilica K. Dermatologia de Pequenos Animais: Atlas Colorido e Guia Terapêuticos. 3 ed. Rio de Janeiro: Elsevier; 2012.

13. Lener DD. Complexo Granuloma Eosinofílico em Felinos Domésticos.[Monografia para Conclusão do Curso de Medicina Veterinária]. Porto Alegre: Universidade Federal do Rio
Grande do Sul; 2013. 53p.

14. Raskin RE. Pele e Tecido Subcutâneo (Placa eosinofílica). In: Raskin RE \& Mayer DJ: Citologia Clínica de Cães e Gatos, Atlas colorido e Guia de Interpretação. 2a ed. Rio de Janeiro: Elsevier; 2013. p. $30-31$.

15. Mason, Burton. Complejo granuloma eosinofilico. In: GUAGUÈRE,E. \& PRÉLAUD, P. Guia Práctica de Dermatología Felina. Merial, 1999, p. 21-29.

16. Grace SF. Complexo Granuloma Eosinofílico. In: Norsworthy G: Paciente Felino. São Paulo: Manole; 2004. p. 232-35. 